\title{
Dados urbanísticos: Quem controla o que sabemos sobre as favelas?
}

\section{Clarissa Freitas}

Clarissa F. Sampaio Freitas coordena do Programa de Pós-Graduação em Arquitetura, Urbanismo e Design da UFC (ppgaud.arquitetura. ufc.br). Desde seu mestrado (UIUC, 2003), tem usado a produção de dados urbanísticos para evidenciar questões urbanas invisibilizadas, como o impacto do modelo de urbanização elitista sobre o quadro natural urbano, e as injustiças espaciais enfrentadas pelos moradores de assentamentos precários. Trabalhou na equipe de implementação do Programa Habitar Brasil nos primeiros anos do Ministério das Cidades em Brasília, onde também cursou Doutorado (UNB, 2009). Foi professora visitante no Departamento de Planejamento Urbano da Universidade de Illinois em Urbana-Champaign (2016), e membro do conselho administrativo da Urban Affairs Association. Atualmente é revisora de periódicos nacionais e internacionais e conduz projetos de extensão universitária no combate à vulnerabilidade socioambiental. clarissa@arquitetura.ufc.br

1 Em Fortaleza, o controle sobre representação do desenvolvimento urbano pelos grupos dominantes explica, por exemplo a apropriação privada de espaços destinados à praças pelos projetos de loteamento. Um exemplo deste processo esta relatado em: http://pet.arquitetura. ufc.br/2018/05/as-normas-de-parcelamento-do-solo-para.html

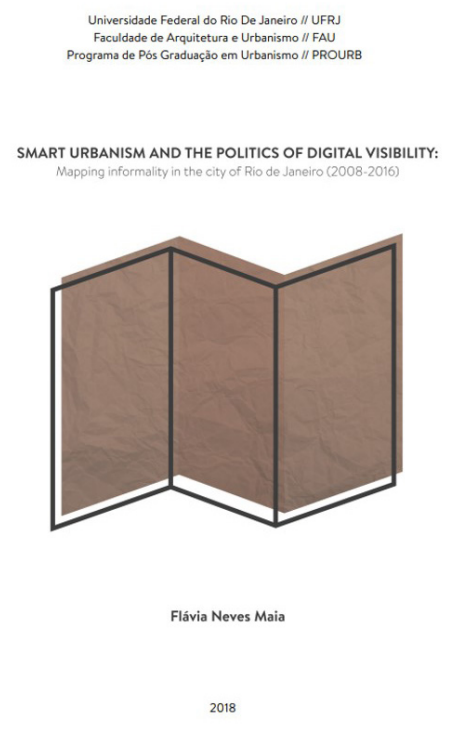

Obra resenhada: MAIA, Flavia Neves. "Urbanismo smart e a política da visibilidade digital: mapeando informalidade na cidade do Rio de Janeiro (2008-2016)" Tese de Doutorado. Rio de Janeiro: PROURB - UFRJ, 2018. Orientação: Rachel Coutinho Marques da Silva. Menção honrosa Prêmio CAPES de TESE 2019

$\mathbf{T}$ odo processo decisório coletivo parte de um denominador comum de conhecimento sobre o assunto em discussão. A pauta do desenvolvimento urbano requer que as informações sejam espacializadas, caso contrário perde-se a relação entre os processos sociais e as transformação do ambiente construído. Até pouco tempo, a produção de plantas, croquis e mapas demandava muitos recursos, e por essa razão a atividade era facilmente monopolizada pelos grupos dominantes, via de regra agentes estatais ou setores privados interessados em influenciar os rumos do processo de produção da cidade ${ }^{1}$. O atual contexto de digitalização das relações sociais desestabiliza o processo tradicional de representação das questões urbanas adicionando novas camadas de desigualdades, cujos efeitos estamos apenas começando a desvendar. Entre uma visão celebratória - que pressupõe o potencial democratizante da produção e manipulação de dados digitais - e uma visão pessimista - que considera inexorável o controle da esfera pública por corporações privadas - há um interessante debate. A dissertação de Flavia Maia, intitulada "Urbanismo smart e a políti- 
ca da visibilidade digital: mapeando informalidade na cidade do Rio de Janeiro (2008-2016)", contribui para avançarmos, adicionando nuances importantes à esta discussão.

Em seu percurso de construir um argumento científico, a autora apoia-se em Foucault para diferenciar os termos "visibilidade" (the quality or state of being visible) do termo Visualização (formation of mental visual images), este último é usado de forma mais recorrente pela ciências exatas. Ao adotar o termo "visibilidade" para descrever os efeitos dos mapeamentos digitais das favelas, a autora minimiza a importância da discussão sobre o recurso tecnológico mais adequado, e põe em evidencia a questão "quem decide que informação será produzida?". Discute assim as formas de representação do espaço construído tão intrínsecas à atividade do arquiteto.

É da natureza da representação iluminar determinados aspectos em detrimento de outros: uma boa representação é aquela que atende aos objetivos pretendidos. Os diversos grupos sociais possuem objetivos diferenciados sobre o uso e a transformação da cidade: uma solução urbanística para uns pode ser um problema para outros. Assim, ao escolher a discussão da visibilidade, a autora aborda a relação entre

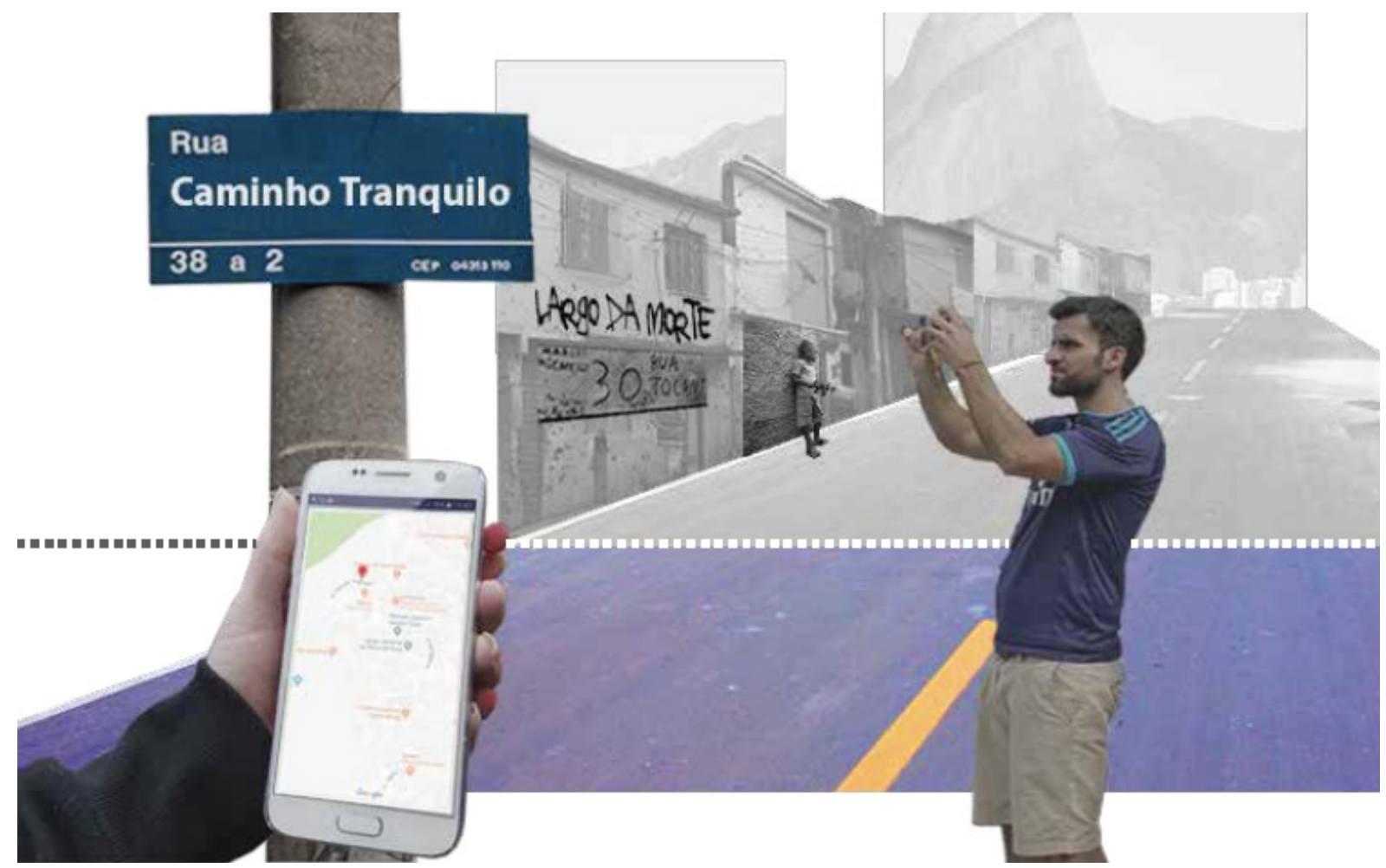

Figura 01

Iniciativas de mapeamento de favelas analisadas pela autora Fonte: Maia, 2018 
poder e conhecimento na ciência do urbanismo: um aspecto chave no processo decisório sobre a cidade, ainda pouco explorado pelo pensamento urbanístico brasileiro.

Para discutir a questão da visibilidade urbanística não consigo pensar em um objeto empírico mais adequado do que o adotado: as favelas. A discussão sobre a representação espacial das favelas brasileiras possui um alto potencial científico, tendo em vista que as cidades que costumam informar o debate teórico internacional localizam-se em países do norte global, onde o fenômeno da informalidade, embora presente, não possui o caráter estrutural como nas cidades periféricas. O trabalho aproxima-se em particular daquelas comunidades de localização mais central no contexto intra-urbano do Rio de Janeiro, cujas narrativas estiveram em franco processo de disputa num momento onde a cidade era uma das vitrines mundiais devido aos Jogos Olímpicos. Embora diversas iniciativas de mapeamento digital das favelas tenham se iniciado bem antes, esse processo se altera com a entrada do Google durante os preparativos para os jogos. Neste momento, alguns representantes comunitários passam a questionar a preferência do Google por sistematizar dados sobre o setor produtivo local, deixando de lado aspectos que carregariam um caráter de denúncia, como a localização das precariedades urbanas (i.e. pontos de acúmulo de lixo), ou os lugares que testemunharam episódios de violência policial.

Segundo as evidências trazidas no trabalho, a iniciativa de mapeamento do Google minimiza a perspectiva dos moradores, se comparada às iniciativas prévias, em grande parte, lideradas pelas próprias associações de moradores. O trabalho insere-se na discussão internacional do "critical smart urbanism" que enfatiza a necessidade de que a visibilidade seja considerada uma categoria das ciências sociais e uma dimensão do exercício de poder. Seu principal argumento é o de que o aumento da visibilidade "per se" não produz inclusão, pois o que importa é quem decide quais aspectos serão visibilizados, ou seja, quem controla a forma como as questões urbanas são compreendidas pela sociedade.

Considero esta argumento extremamente adequado aos objetivos pretendidos, e ao diálogo com a literatura do "critical smart urbanism". Entretanto ele está ainda aquém da nossa tarefa coletiva enquanto arquiteto/urbanista na sociedade brasileira de apontar caminhos para qualificar o ambiente construído. Comprovar que os desafios das favelas têm sido defini- 
do de forma equivocada é o primeiro passo (talvez o mais importante) na direção de construir caminhos para superá-los. E nesta empreitada coletiva, não podemos que associar inevitavelmente a utilização das novas tecnologias de produção e manipulação de dados espaciais a um processo decisório tecnocrático e excludente. Em momento algum o trabalho caiu nessa armadilha, porém deixou em aberto uma discussão do potencial dos "novos meios" no combate à reprodução das desigualdades urbanas. Neste sentido a aproximação do trabalho com o tema do projeto urbanístico pode ser frutífero.

A entrada do Google no processo de mapeamento das favelas no Rio de Janeiro assemelha-se ao que Miraftab denomina "dominação pela inclusão", ou seja, uma estratégia associada ao urbanismo neoliberal onde as formas de dominação são mais fluidas e dinâmicas que em um período anterior de estado forte (Miraftab, 2012). Este atual paradigma incorpora a linguagem da inclusão (como a participação dos moradores na produção dos dados) para justificar a manutenção de vulnerabilidades de grupos historicamente excluídos. O objetivo legítimo de aumentar a quantidade de informações espaciais das favelas para conferir cidadania aos moradores foi instrumentalizado para "colonizar" um território que historicamente simbolizou resistência, e representou uma alternativa ao modo de urbanização capitalista. Assim, na iniciativa do Google, a visibilização de aspectos que denunciam o dever do estado em garantir os direitos urbanos mínimos àquela população foi preterida, contribuindo para perpetuar nos moradores um status de cidadania incompleta, sempre existente, porém agora com uma nova roupagem (Freitas, 2019). Para os defensores desta iniciativa, o acesso às condições urbanas mínimas se daria pelo aumento do poder de compra das famílias cujos negócios fossem mapeados, afastando-se da noção de direitos humanos fundamentais.

Nesta disputa de narrativas sobre a favela (entre espaço de precariedade e berço de empreendedores), outras características do espaço construído devem ser consideradas, para além da localização das atividades econômicas. A disposição do sistema viário, a organização espacial dos lotes na quadra, a relação entre edifício e lote, a delimitação das áreas de recuperação ambiental e o tratamento dos espaços de convivência comunitária são aspectos fundamentais para que o direito à cidade seja efetivado, independente da condição econômica do morador. Sigo crendo que as novas tecnologias são uma grande oportunidade 

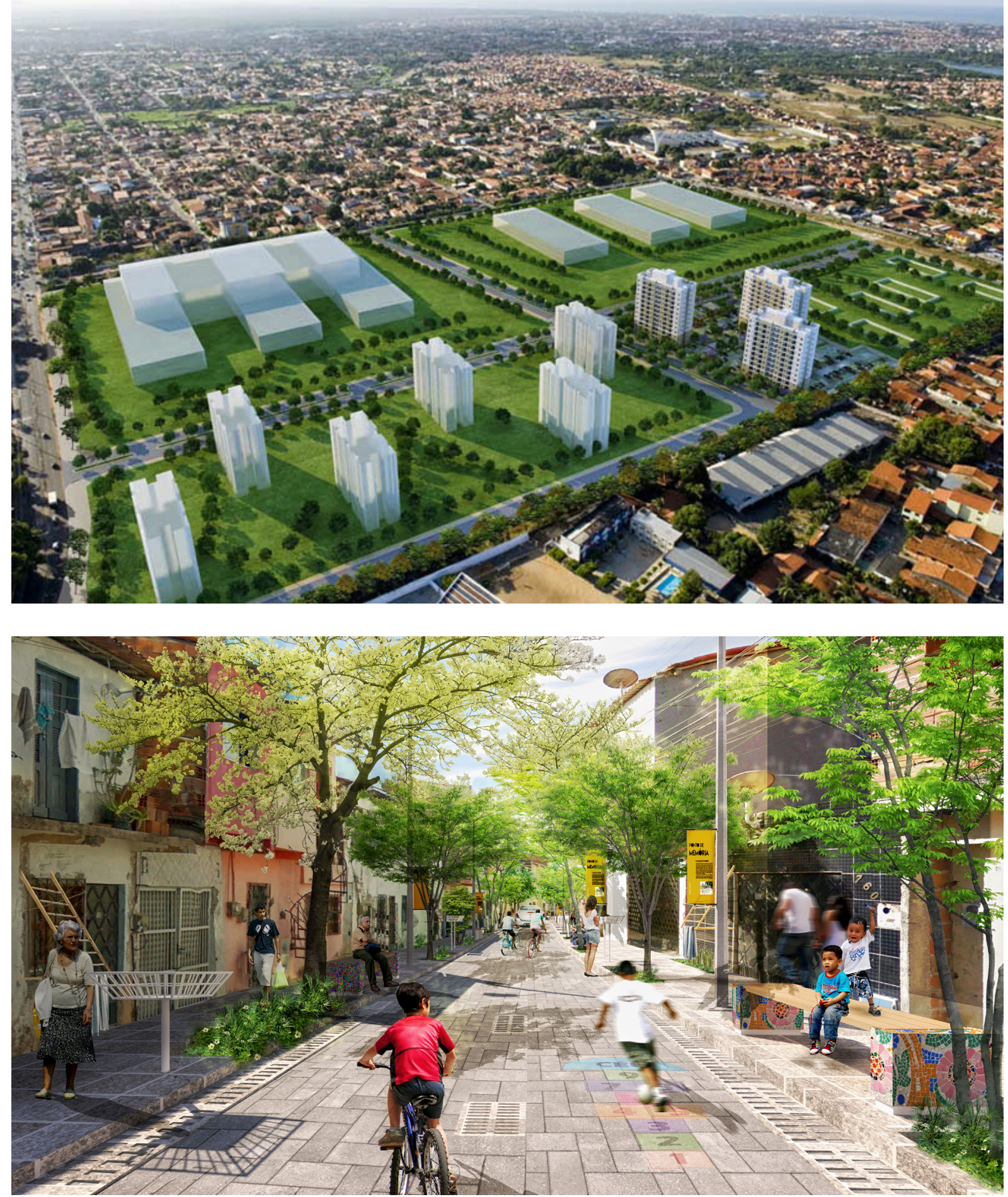

Figura 02

A disputa de narrativas e a solução urbanística para a favela Fonte: Acima: Empreendimento imobiliário aprovado para um terreno próximo à ZEIS do PICI. http://vivendasjoqueiville.blogspot.com/2015/01/ vivendas-joquei-ville-o-melhor-pedaco.html (acesso em 25/08/2020) Abaixo: Representação das propostas de urbanização do assentamento informal do Pici, elaborada por Shaiane Gomes Viana para compor o Plano Integrado de Regularização Fundiária da ZEIS do Pici, em Cetrede-UFC-Iplanfor, 2020 
para desestabilizar o monopólio da produção de conhecimento sobre a cidade, e em particular sobre sua forma de organização espacial. Usar os novos meios para sistematizar dados sobre a morfologia urbana da favela, pode produzir um poderoso instrumento, uma espécie "urbanismo denúncia" que privilegia a ótica do morador, historicamente invisibilizada. Neste sentido, pesquisas brasileiras têm muito a contribuir. Tanto os métodos pioneiros de leitura da malha viária dos assentamentos precários em Belém (Cardoso, 2007) até trabalhos mais recentes que incorporam modelagem urbana para descrever e simular parâmetros de controle urbanísticos (Costa Lima et al., 2019) revelam que os "novos meios" podem sim ser usados para informar o debate urbanístico sobre o direito à cidade nas favelas apontando soluções projetuais. Além de evitar que novas formas de dominação colonizem os nossos sonhos, não podemos (coletivamente) prescindir de representar o futuro desejado, caso contrário ele nunca se efetivará.

\section{Referências}

Cardoso, A. C. D. (2007). O espaço alternativo: Vida e forma urbana nas baixadas de Belém. Editora Universitária UFPA.

Costa Lima, M. Q., Freitas, C. F. S., Cardoso, D. R., Lima, M. Q. C., Freitas, C. F. S., \& Cardoso, D. R. (2019). Modelagem da informação para a regulação urbanística dos assentamentos precários em Fortaleza. urbe. Revista Brasileira de Gestão Urbana, 11. https://doi. org/10.1590/2175-3369.011.e20180199

Freitas, C. F. S. (2019). Insurgent planning? Insights from two decades of the Right to the City in Fortaleza, Brazil. City: analysis of urban trends, culture, theory, policy, action, 23(3), 285-305. https://doi.org/10.1080/13604813.2019.1648030

Miraftab, F. (2012). Planning and Citizenship. In The Oxford handbook of urban planning (p. 1180-1204). https://urban.illinois.edu/images/miraftabPDFs/Miraftab-OHP-final.pdf 